Full Length Article

\title{
Temporary and permanent changes to the defect equilibrium due to ultraviolet exposure: Surface and bulk effects on $\mathrm{ZnO}$ nanostructures
}

\author{
Sesha Vempati ${ }^{\mathrm{a}, *}$, Sefika Ozcan ${ }^{\mathrm{a}, \mathrm{b}}$, Tamer Uyar ${ }^{\mathrm{a}, \mathrm{c}}$ \\ a UNAM-National Nanotechnology Research Center, Bilkent University, Ankara 06800, Turkey \\ ${ }^{\mathrm{b}}$ Department of Polymer Science and Technology, Middle East Technical University, Ankara 06800, Turkey \\ ${ }^{\mathrm{c}}$ Institute of Materials Science \& Nanotechnology, Bilkent University, Ankara 06800, Turkey
}

\section{A R T I C L E I N F O}

\section{Keywords:}

Core-level

Valence band structure

Defect migration

Interstitial hydrogen

Oxygen vacancy

\begin{abstract}
A B S T R A C T
We report on the influence of prolonged exposure of above band gap illumination (UV) on the surface electronic structure (core and valence band) and bulk defect equilibrium of $\mathrm{ZnO}$ nanorods. We investigated two samples (ZnO1 and $\mathrm{ZnO} 2$ ) of mutually contrasting surface electronic structure as well as photoluminescence responses. The changes due to the above gap exposure were juxtaposed of as-prepared, UV-treated and healed samples. As prepared samples consist of CC, $\mathrm{COC}$ and $\mathrm{COOH}$ groups at the surface. The intrinsic surface/defect mediated photocatalytic activity under UV-illumination regenerated the lattice oxygen, oxidized the excess zinc and increased the $\mathrm{COC}$ fraction. The surface of $\mathrm{ZnO} 2$ was catalytically more active than that of $\mathrm{ZnO} 1$ due to zinc interstitials $\left(\mathrm{Zn}_{i} \mathrm{~s}\right)$ and extended $\mathrm{Zn}_{i} \mathrm{~s}\left(\mathrm{ex}-\mathrm{Zn}_{i} \mathrm{~s}\right)$. Also, we identify chemisorbed oxygeneous species, interstitial hydrogen $\left(\mathrm{H}_{i}{ }^{+}\right)$, multidentate complexes and disassociated $\mathrm{O}_{2}$ molecule at oxygen vacancies $\left(V_{\mathrm{O}}\right)$. As a result of the catalytic activity severe changes occurred to the valance band (VB) edge and deeper-VB structure. After the course of healing, the $\mathrm{VB}$ edge for $\mathrm{ZnO} 1$ recovered to its pristine condition, unlike $\mathrm{ZnO} 2$. Additionally, we note increased fraction of $\mathrm{O} 2 \mathrm{~s}$ component for both the samples which, after healing did not recover to their as prepared condition. In the context of defect equilibrium the UV-treatment reduced the density of charged oxygen vacancy $\left(V_{O}{ }^{\delta}\right)$ and the thickness of the depletion layer which we attribute to the desorption of some chemisorbed gases and reconstruction of lattice oxygen. For $\mathrm{ZnO} 1, \mathrm{ex}^{-} \mathrm{Zn}_{i} \mathrm{~s}$ are induced after UV-treatment, which subdued to an extent in the course of healing. In sharp contrast, for $\mathrm{ZnO} 2$ the UV-treatment subdued the ex- $\mathrm{Zn}_{i}$ related emission, which slightly recovered after healing in addition to a further loss of $V_{\mathrm{O}}{ }^{\delta}$ related emission. The slow recovery and reorganization of intrinsic defects are attributed to the diffusivity of $\mathrm{H}_{i}{ }^{+}$and the associated lattice distortion, and $\mathrm{Zn}_{i} \mathrm{~s}$ in the neighborhood of $V_{\mathrm{O}} \mathrm{s}$. Furthermore, the non-Coulombic attractive interaction between neutral $V_{\mathrm{O}} \mathrm{s}$ and $\mathrm{Zn}_{i} \mathrm{~s}$ mediate the migration of defects and subsequent stabilization on slower timescales. The changes due to UV illumination on the electronic structure and defect equilibrium enhance the applicability and understanding of $\mathrm{ZnO}$ nanostructures in optoelectronic applications.
\end{abstract}

\section{Introduction}

Zinc oxide is an important wide band gap semiconductor which is extensively studied for applications ranging from biology [1], optoelectronics [2-4], photocatalysis [5-9], etc. Indeed, the applicability is crucially dependent on the harvesting the photogenerated charge carriers as modulated by the optoelectronic response. Under above band gap illumination, electrons are excited into the conduction band (CB) leaving the holes in the valence band (VB). The photogenerated charge carriers are extracted at the surface [10] or at interface for catalytic or optoelectronic applications, respectively. i.e. the photogenerated charge carriers are utilized when $\mathrm{ZnO}$ is submerged in a test solution
[7-9], interfaced $[1,4]$ or in other conditions $[1,6]$, under prolonged exposure of above band gap illumination (UV-light in the case of $\mathrm{ZnO}$ ). Furthermore, the applicability of $\mathrm{ZnO}$ crucially hinges on the density and distribution of intrinsic defects and their effects on optoelectronic properties, where the photogenerated charge carriers can be trapped at a localized intrinsic defect [2,5-9]. The intrinsic defects include zinc interstitials $\left(\mathrm{Zn}_{i} \mathrm{~s}\right)$ extended zinc interstitials $\left(e x-\mathrm{Zn}_{i} \mathrm{~s}\right)$, oxygen vacancies $\left(V_{\mathrm{O}} s\right)$ to name a few [11]. In any case, understanding the defect equilibrium, electronic structure and optoelectronic properties are inevitable when $\mathrm{ZnO}$ is subjected to prolonged exposure to above gap illumination. This can be studied at two contexts, such as 'surface' and 'bulk'. Under extended above gap illumination, various photon-assisted

\footnotetext{
* Corresponding author.

E-mail address: svempati01@qub.ac.uk (S. Vempati).
} 

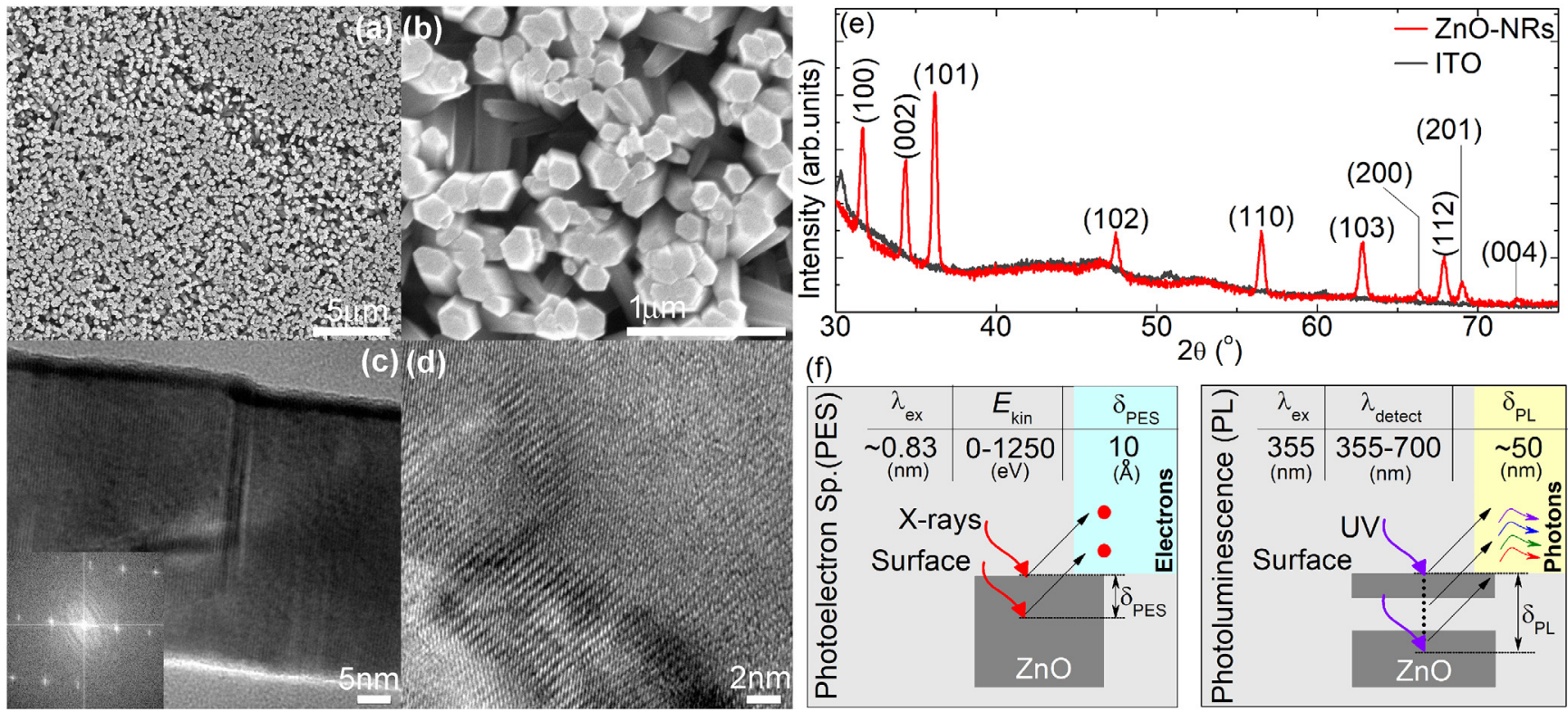

Fig. 1. Micrographs of ZnO nanorods recorded (a) and (b) with SEM, while (c) and (d) under TEM. Inset of (c) shows FFT image of (d). (e) XRD pattern with various diffraction planes of $\mathrm{ZnO}$ annotated and (f) compares the probe depths, $\delta_{\mathrm{PES}}$ and $\delta_{\mathrm{PL}}$ respectively from photoelectron spectroscopy (PES) and photoluminescence (PL). $\lambda_{\text {ex }}$-excitation wavelength, $E_{\text {kin }}$ kinetic energy of electrons and $\lambda_{\text {detect }}-$ detection range of emission wavelength.

surface reactions were discussed in the literature, as noted in the following. These include (a). desorption of the surface oxygen and decrease of the surface depletion depth [12,13], (b). release of captured electrons from surface states [14-16], generating $V_{\mathrm{O}} \mathrm{s}[14,17,18]$, (c). lattice decomposition and formation of Zn-rich surface [19] etc. Notably, points (b) and (c) depend on the catalytic activity of the surface, where defect density $[7,8]$, type of defect [8], reactivity [8], play a crucial role. In summary, the effects of the UV treatment are believed to be surface limited, however, we find that the effects can be extended into the bulk and alters the defect equilibrium as well as surface electronic structure.

In this study, we compared samples of mutually contrasting optical character, which differ in the relative concentration of $\mathrm{Zn}_{i} \mathrm{~s}$ and $V_{\mathrm{O}} \mathrm{s}$. In both the samples, the changes to the electronic structure as well as the defect equilibrium were two fold. We find that some of the changes were reversible to that of as-prepared condition, while others were permanent after one week of healing process. We showed that the UVtreatment oxidizes the Zn-rich surface with a regeneration of lattice oxygen and $\mathrm{COC}$ functional groups in addition to some significant changes to the VB structure and core-levels. This study unveiled various permanent and temporary effects of prolonged exposure of above band gap illumination on the surface and bulk optoelectronic properties, thereby enhancing applicability of zinc oxide.

\section{Experimental}

ZnO nanorods (ZnO-NRs) were deposited on clean ITO coated polyethylene terephthalate (60 $\Omega /$ sq, Sigma Aldrich) substrates via electrodeposition as described in Ref. [20] Briefly, equimolar hexamethyl tetramine (HMT) and $\mathrm{ZnNO}_{3} \cdot 6 \mathrm{H}_{2} \mathrm{O}$ aquous solution is heated to $\sim 94^{\circ} \mathrm{C}$. Typically, about $10 \mathrm{~mm}$ along the length of ITO substrate was immersed into the electrolyte. The distance between ITO and counter electrode $\left(10 \times 15 \mathrm{~mm}^{2}\right)$ was set to $\sim 15 \mathrm{~mm}$. The depositon was carriedout at $-2.5 \mathrm{~V}$ followed by $-2.1 \mathrm{~V}$ (with respect to a stainless steel counter electrode) to facilitate the formation of a seed layer ( $0.5 \mathrm{~min})$ and the growth of nanorod ( $5 \mathrm{~min}$ ), respectively.

Surface morphology of the ZnO-NRs was studied using a scanning electron microscope (SEM, FEI-Quanta 200 FEG). For transmission electron microscopy (TEM, FEI-Tecnai G2F30) imaging, ZnO-NRs were removed from the substrate by scraching with a sharp blade. The collected powder-like substance was sonicated in ethanol for $<1 \mathrm{~min}$. A drop of this dispersion is collected on a holey carbon coated TEM grid and subjected to analyses. Fast Fourier Transform (FFT) of HR-TEM image was obtained with Image $\mathrm{J} 1.42 \mathrm{q}$ software. X-ray diffraction (XRD) patterns were collected $\left(2 \theta=30^{\circ}-75^{\circ}\right)$ using PANalytical X'Pert Pro MPD X-ray Diffractometer using CuKa radiation $(\lambda=1.5418 \AA)$. Valence and corel-level photoelectron spectroscopy (PES) was performed with AlKa line ( $\mathrm{h} v=1486.6 \mathrm{eV}$ or $\sim 0.83 \mathrm{~nm}$, Thermoscientific, $\mathrm{K}$-Alpha) in the presence of a charge neutralizer. During the XPS data acquisition, a metal clip connected the sample to the sample holder via the uncoated ITO surface. Note that the sample holder is in contact with the ground. All photoelectron spectra were angle-integrated, i.e. each spectrum contains contributions from phtoelectrons of all escape angles and various crystal planes of the almost vertically standing nanorods. For peak deconvolution (Avantage software) the number of peaks was chosen based on the chemistry of the surface while the spectral location and full width at half maximum (FWHM) were allowed to vary. Photoluminescence (PL) spectra were recorded (Horiba Scientific FL1057 TCSPC) at an excitation wavelength $\left(\lambda_{\text {ex }}\right)$ of $355 \mathrm{~nm}$. Peak-fits were performed on the normalized PL spectra with Origin 8.5. Peak centers for charged $V_{\mathrm{O}}\left(V_{\mathrm{O}}^{\delta}\right)$-related emission $(527 \mathrm{~nm}$ and $571 \mathrm{~nm})$ were fixed based on the literature and other parameters were allowed to vary $[3,11]$. After deconvolution, the centres of the other peaks contain a finite error of about $\pm 2 \mathrm{~nm}$. We have investigated zinc oxide samples of two different PL characteristics which were referred to as $\mathrm{ZnO} 1$ and ZnO2. Above band gap or UV-Vis illumination $(300 \mathrm{~W}$, Ultra-Vitalux lamp, Osram) was carried out for $30 \mathrm{~min}$ from a distance of $12 \mathrm{~cm}$ from the source through $\sim 5 \mathrm{~cm}$ of water column to eliminate the IR component. XPS and PL analyses were performed on pristine samples, UV treated counterparts and after one week of healing in ambient atmosphere. These samples are referred to as $\mathrm{ZnO1(2),}{ }^{\mathrm{aUV}} \mathrm{ZnO1(2)}$ and ${ }^{\mathrm{huv}} \mathrm{ZnO1}(2)$, respectively. ${ }^{\mathrm{aUv}} \mathrm{ZnO} 1$ and ${ }^{\mathrm{aUv}} \mathrm{ZnO} 2$ samples were transferred into the XPS analyses chamber almost immediately after the UV treatment. The difference PL response was defined as $\Delta^{\mathrm{a}(\mathrm{h}) \mathrm{UV}} \mathrm{ZnO1}(2)={ }^{\mathrm{a}(\mathrm{h}) \mathrm{UV}} \mathrm{ZnO} 1(2)-\mathrm{ZnO}(1) 2$ and implemented on normalized spectra. 
Table 1

Elemental composition shown in atomic percent as obtained from XPS survey spectra.

\begin{tabular}{|c|c|c|c|c|c|c|c|c|}
\hline \multirow[t]{2}{*}{ Elements } & \multicolumn{3}{|c|}{ Sample 1} & \multirow[t]{2}{*}{ Net change after healing } & \multicolumn{3}{|c|}{ Sample 2} & \multirow[t]{2}{*}{ Net change after healing } \\
\hline & $\mathrm{ZnO1}$ & ${ }^{\mathrm{auv}} \mathrm{ZnO1}$ & ${ }^{\mathrm{huv}} \mathrm{ZnO1}$ & & $\mathrm{ZnO} 2$ & ${ }^{\mathrm{auv}} \mathrm{ZnO2}$ & ${ }^{\mathrm{huv}} \mathrm{ZnO} 2$ & \\
\hline Zn (\%) & $74.01 \pm 2.22$ & $73.56 \pm 2.20$ & $69.57 \pm 2.08$ & Decrease & $76.56 \pm 2.29$ & $69.22 \pm 2.08$ & $70.95 \pm 2.13$ & Decrease \\
\hline $\mathrm{O}(\%)$ & $15.74 \pm 0.47$ & $16.57 \pm$ & $17.43 \pm 0.53$ & Increase & $15.87 \pm 0.48$ & $21.97 \pm 0.66$ & $18.67 \pm 0.56$ & Increase \\
\hline C (\%) & $10.23 \pm 0.31$ & $9.88 \pm 0.29$ & $13.00 \pm 0.39$ & Increase & $7.57 \pm 0.23$ & $8.81 \pm 0.26$ & $10.38 \pm 0.31$ & Increase \\
\hline
\end{tabular}

\section{Results and discussion}

\subsection{Morphology and crystal structure}

Representative SEM images from ZnO1 are shown in Fig. 1a and b at two different mangifications. These nanorods showed a well-defined hexagonal shape with a width varying from $180 \mathrm{~nm}$ to $240 \mathrm{~nm}$. SEM image with higher magnification depicted grain like features on top of the nanorod which is typical and expected in nanostructures grown via electrodeposition. HR-TEM imaging is performed on the nanorods which unveiled the growth direction to be the $c$-axis of the $\mathrm{ZnO}$ (Fig. 1c and d). Furthermore, Fig. 1d is recorded at much higher magnification depicting well resolved lattice planes. We have generated a FFT image of Fig. 1d and shown as an inset of 1c. The rectangular symmetry of the spots is an indication of well developed lattice along $c$-axis of $\mathrm{ZnO}$, which is comparable to that of an earlier observation from $\mathrm{ZnO}$ nanorods [7]. Although TEM is a local probe, nicely resolved lattice planes is a clear indication of well developed crystal structure. Also, the interplanar spacing of $\sim 0.5 \mathrm{~nm}$ is consistent with the literature [7]. We have compared $\mathrm{ZnO} 1$ and $\mathrm{ZnO} 2$ samples and we find that the morphology and surface coverage of are indistinguishable (results not shown here).

XRD patterns from ZnO-NRs and ITO substrate are shown in Fig. 1e, where the diffraction planes for the former are annotated. The diffraction peaks represent a hexagonal wurtzite structure, which is consistent with the data base (ICDD 01-074-9940). XRD pattern from nanostructures needs a precise inspection in terms of lattice parameters, especially when grown on substrates with large lattice mismatch such as ITO, silicon etc. The calculated lattice parameters are, $a=3.266 \AA$ and $c=5.229 \AA$, yielding a ratio of $(c / a)=1.601$ in line with wurtzite crystal structure ( $c f$ theoretical value $=\sqrt{ }(8 / 3)$ ). We compared the lattice parameters with that of literature which suggested some 'stress' that is associated with the defects and/or the substrate (ITO/PET) [7]. It is important to note the presence of the seed layer just underneath the nanorods (direclty grown on the ITO substrate). The diffraction pattern has contribution from the seed layer as well, where perhaps the strain is maximum. However, in the present context, we cannot either confirm or deny any strain within nanorods. In any case, the changes to the lattice parameters are attributed to the effect from the substrate. Also, within the detection limits of XRD, we did not observe diffraction peaks associated with impurities or reactants.

As motivated in the introduction, we would like to investigate the changes to the surface electronic structure and bulk optical properties of ZnO-NRs. Hence the probe depths of PES and PL techniques need to be discussed. In Fig. 1f, $\delta_{\mathrm{PES}}$ and $\delta_{\mathrm{PL}}$ indicate probe depths of PES and PL, respectively. In the context of XPS photoemitted electrons are detected. The relatively short escape depth $\left(\delta_{\mathrm{PES}}\right)$ of photoelectrons makes the PES rather surface sensitive. $\delta_{\mathrm{PES}}$ is derived from the universal curve of photoelectrons with reference to their kinetic energy, $E_{\text {kin }}$ [21]. For core-level and valence band, the $\delta_{\mathrm{PES}}$ varies from $1 \mathrm{~nm}\left(E_{\mathrm{kin}} \approx 1 \mathrm{keV}\right)$ to $3 \mathrm{~nm}\left(E_{\mathrm{kin}} \approx 8 \mathrm{eV}\right)$, respectively. In both the cases, the core and valence electronic structures are limited to the surface, where the role of adsorbants, functional groups, changes to the atomic composition can be studied. On the other hand, for PL, $\lambda_{\text {ex }}$ of $355 \mathrm{~nm}$ penetrates as deep as $\sim 50 \mathrm{~nm}$ below the surface (characteristic length for an optical absorption coefficient of $2 \times 10^{5} \mathrm{~cm}^{-1}$ at $355 \mathrm{~nm}$, Ref. [22]). Hence, the isotropic luminescence occurs from $>50 \mathrm{~nm}$ below the surface. Radiative transitions and changes to the surface depletion layer associated with intrinsic defects can be probed with PL spectroscopy $[3,11]$. Now, we start our discussion with surface electronic structure and then move on to the bulk-related-properties.

\subsection{Surface electronic structure}

Changes to the surface composition after UV treatment and subsequent healing are discussed in the following, before going into the details of the electronic structure. The atomic percentages of various elements were evaluated from the XPS survey spectra (not shown here) and the results are tabulated in Table 1. From Table 1, we note a loss (gain) of $\mathrm{Zn}(\mathrm{O})$ at $\%$ after $\mathrm{UV}$ treatment and subsequent healing process. The increase of oxygen content is generally ascribed to a net increase of defect density at the surface. However, we will see from the core-level spectra that the increase is indeed associated with lattice oxygen. Note that the survey-analysis does not distinguish lattice oxygen from that of chemisorbed species. Nevertheless, these defects host $-\mathrm{OH},-\mathrm{CO}$, $\mathrm{CO}_{2}{ }^{-\alpha}$, adsorbed $\mathrm{H}_{2} \mathrm{O}$ and/or $\mathrm{O}_{2}$ or $\mathrm{O}^{-}$and $\mathrm{O}^{2-}$ ions [6,8]. Interestingly, after UV irradiation the carbon contamination at the suface is decreased(increased) in the case of $\mathrm{ZnO}(\mathrm{ZnO} 2)$. The carbon at $\%$ includes chemisorbed gases like $\mathrm{CO}_{2}{ }^{-\alpha}$ and other strongly bound functional groups, which will be discussed further in relation to the corelevel analyses.

Fig. 2 shows C1s-spectral region for three cases, viz pristine, UVtreated and healed samples. The core-level spectra depict three-peak structures irrespective of the course of the treatment, where the peak BE values are annotated on the spectra. The spectral feature at lower energy $(\sim 285 \mathrm{eV})$ with relatively higher intensity is attributed to $\mathrm{C}-\mathrm{C}$ bonds, while the other two lower intensity peaks at $\sim 286$ and $\sim 288 \mathrm{eV}$ are attributed to $\mathrm{C}-\mathrm{O}-\mathrm{C}$ and $\mathrm{O}-\mathrm{C}=\mathrm{O}$, respectively. The binding energy values are consistent with the data base [23]. The fractional

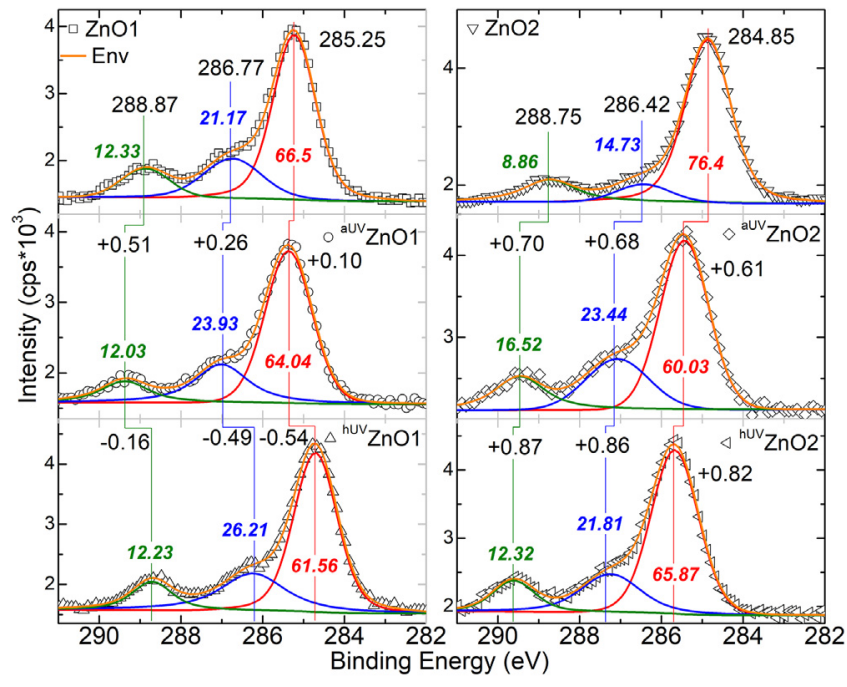

Fig. 2. C1s core-level spectra from $\mathrm{ZnO}$ nanorods. Spectral locations of the peaks and their shift with reference to untreated samples are indicated in $\mathrm{eV}$. Atomic percentage of each functional group is annotated in italics. 
contribution (\%) of each of the functional groups is annotated on the spectra in italics. The atomic percentage of $\mathrm{C}-\mathrm{C}$ group is decreased after UV-treatment for both the samples; however, $\mathrm{ZnO} 2$ exhibited higher initial carbon content. On the other hand, $\mathrm{C}-\mathrm{O}-\mathrm{C}$ at $\%$ increased after UV-treatment. Shapira et al. [24] argued that lattice oxygen desorbs in the form of $\mathrm{CO}_{2}$ upon above band gap excitation of $\mathrm{ZnO}$, for which the carbon at the surface should be catalytically active. The catalytic acitivity of the $\mathrm{ZnO}$ surface is already known, and indeed $\mathrm{C}-\mathrm{O}-\mathrm{C}$ groups might have generated from the oxidation of $\mathrm{C}-\mathrm{C}$ (the exact oxidation mechanism is still to be unveiled). Interestingly, the $\mathrm{O}-\mathrm{C}=\mathrm{O}$ at $\%$ did not vary significantly on the surface of $\mathrm{ZnO} 1$ which is in contrast to that of $\mathrm{ZnO} 2$. The regeneration and variation to the density of oxygeneous groups are clear indications of the catalytically active surfaces, where the surface defects and their densities play a crucial role [9]. The differences in the chemical nature of catalytically active sites determine the strength of the bond, where for instance, $Z_{i} \mathrm{~s}$ mediate chemisorption of acidic groups more strongly than that of stoichiometric surface [25]. The consequences of catalytic activity of $\mathrm{ZnO} 2$ will be further explicit in the context of O1s-level and valence band spectra. The variation in the ionic environment is observed as shift of the peak-BE which differ across the samples and also with reference to the UV-treatment. The functional groups depict varying degrees of electron withdrawing nature due to the presence of oxygen with some electronegative character. In general, the blue shift can be attributed to relatively stronger binding of electron to the nucleus. This is true for both the samples after UV-treatment. However, after UV treatment, the magnitude of the blue shift increases for $\mathrm{C}-\mathrm{C}, \mathrm{C}-\mathrm{O}-\mathrm{C}$ and $\mathrm{O}-\mathrm{C}=\mathrm{O}$ for both the samples, where the largest shift is observed for $\mathrm{O}-\mathrm{C}=\mathrm{O}$ group. On the other hand, the red-shift is due to increased density or delocalization of electrons on the functional group. After healing, interestingly, the magnitude of red shift for $\mathrm{ZnO} 1$ increases for $\mathrm{O}-\mathrm{C}=\mathrm{O}$, $\mathrm{C}-\mathrm{O}-\mathrm{C}$ and $\mathrm{C}-\mathrm{C}$, where the highest shift is recorded for $\mathrm{C}-\mathrm{C}$ group. In sharp contrast, $\mathrm{C} 1$ s from $\mathrm{ZnO} 2$ depicted a systematic blue-shift upon UV-treatment and then after healing.

O1s spectra from $\mathrm{ZnO} 1$ and $\mathrm{ZnO} 2$ are shown in Fig. 3, along with atomic percentages for lattice oxygen $\left(\mathrm{O}_{\mathrm{ZnO}}\right)$ and chemisorbed oxygeneous groups $\left(\mathrm{O}_{\mathrm{Ch}}\right)$ annotated in italics. The peak binding energy of $\mathrm{O} 1 \mathrm{~s}$ from $\mathrm{ZnO}$ lattice $\left(\mathrm{O}_{\mathrm{ZnO}}\right)$ is consistent with the literature which confirms the tetrahedral coordination [23]. For $\mathrm{ZnO1}$, the intensity of $\mathrm{O}_{\mathrm{ZnO}}$ depicted a slight increase (decrease) after UV-treatment (healing course). The peak intensity of $\mathrm{O}_{\mathrm{ZnO}}$ component consistently increased in the case

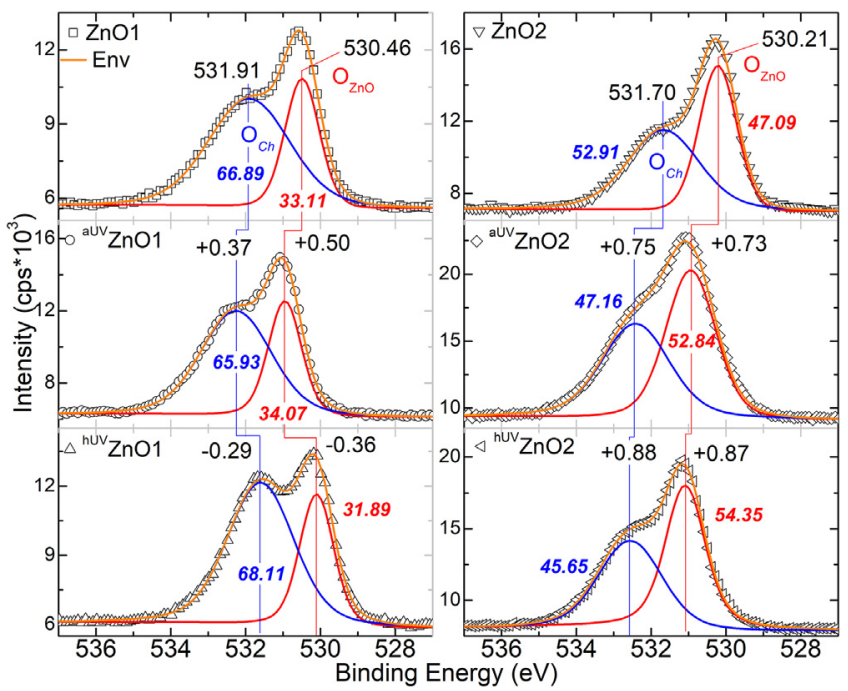

Fig. 3. O1s core-level spectra from ZnO nanorods. Spectral locations of the peaks and their shift with reference to untreated samples are indicated in $\mathrm{eV}$. Atomic percentage of each functional group is annotated in italics. $\mathrm{O}_{\mathrm{Ch}}$-chemisrobed oxygen and $\mathrm{O}_{\mathrm{ZnO}}$-lattice oxygen from $\mathrm{ZnO}$. of $\mathrm{ZnO} 2$ and $\mathrm{ZnO} 1$ during the complete course of UV treatment and healing. This is an indication of reconstructed $\mathrm{ZnO}$ lattice due to the catalytic activity of the surface. Notably, the surface of $\mathrm{ZnO} 1$ is also catalytically active however, lower than that of $\mathrm{ZnO} 2$ (higher fractional increase of $\mathrm{O}_{\mathrm{ZnO}}$ in $\mathrm{ZnO} 2$ ). The $\mathrm{O}_{\mathrm{Ch}}$ component represents a number of chemisorbed oxygeneous functional groups at the surface and defects. The presence of multiple oxygeneous groups constituting the $\mathrm{O}_{C h}$ is reflected in significantly larger FWHM values. These groups include $V_{\mathrm{O}}$, adsorbed $\mathrm{H}_{2} \mathrm{O}, \mathrm{COC}$ and $-\mathrm{COOH}$. Importantly, these groups also consist the species of hydrogen-related, where the hydrogen binds to lattice-oxygen directly (interstitial hydrogen $\left(\mathrm{H}_{i}{ }^{+}\right)$) [2]. Apart from the electron capturing molecules, the oxygen vacancy sites are attractive places for the chemisorption where $\mathrm{O}_{2}$ undergoes a spontaneous and dissociative chemisorption at room temperature (at non-polar surfaces) $[26,27]$. Essentially $V_{\mathrm{O}}$ is filled when an oxygen molecule donates one oxygen atom to the lattice. Furthermore, it is also found that a mixture of $\mathrm{CO}_{2}$ and $\mathrm{H}_{2}$ produce peaks at 532.9 and $531.7 \mathrm{eV}$ with the formation of 'formate' at the surface [28]. $\mathrm{CO}_{2}$ chemisorbs at $\mathrm{ZnO}$ surface in a tridentate configuration mediated by a charge transfer process from the $\mathrm{CB}$ of $\mathrm{ZnO}[6]$. Upon chemisorption, the binding energy of electron from $\mathrm{O} 1 \mathrm{~s}$ orbital of $\mathrm{CO}_{2}$ decreases. Also some contribution to the broadening of FWHM occurs from molecules bound in multidentate configuration [29].

Zn2p core-level spectra are shown in Fig. 4. Peak positions and shifts with respect to pristine sample are indicated on the spectra. Peaks around 1021 and $1045 \mathrm{eV}$ are attributed to $2 \mathrm{p} 3 / 2$ and $2 \mathrm{p} 1 / 2$, respectively. The magnitude of the blue shift is the highest for UV-treated samples ( $\mathrm{ZnO} 1$ and 2). After healing, we note that the magnitude of the blue shift decreased. The blue shift of Zn2p spectra is attributed to the increased degree of oxiation. Indeed the largest shift, after UV-treatment is consistent with the highest fraction of $\mathrm{O}_{C h}$ as well as $\mathrm{O}_{\mathrm{ZnO}}$. The fraction of $\mathrm{O}_{C h}$ and $\mathrm{O}_{\mathrm{ZnO}}$ decreased after healing, as corroborated by the results from O1s spectra. The magnitude of the blue shift is also decreased after healing process. There is in fact, no indication of increased metallic zinc $\left(\mathrm{Zn}^{0}\right)$ content, in which case a red shift is expected. Our results are in sharp contrast to the literature. Gurwitz et al. [19] reported oxygen breathing mechanism of $\mathrm{ZnO}$, upon exposure to white light (Xe arc lamp) under UHV conditions. They have evidenced the formation of $\mathrm{Zn}$ rich surface, which is in fact discussed in the literature much earlier in 1958 [12]. We acknowledge the fact that if the surface is turned richer in $\mathrm{Zn}$, it may be explicit with XPS as we reported earlier [3]. Currently, within the probe depth there is no indication for the

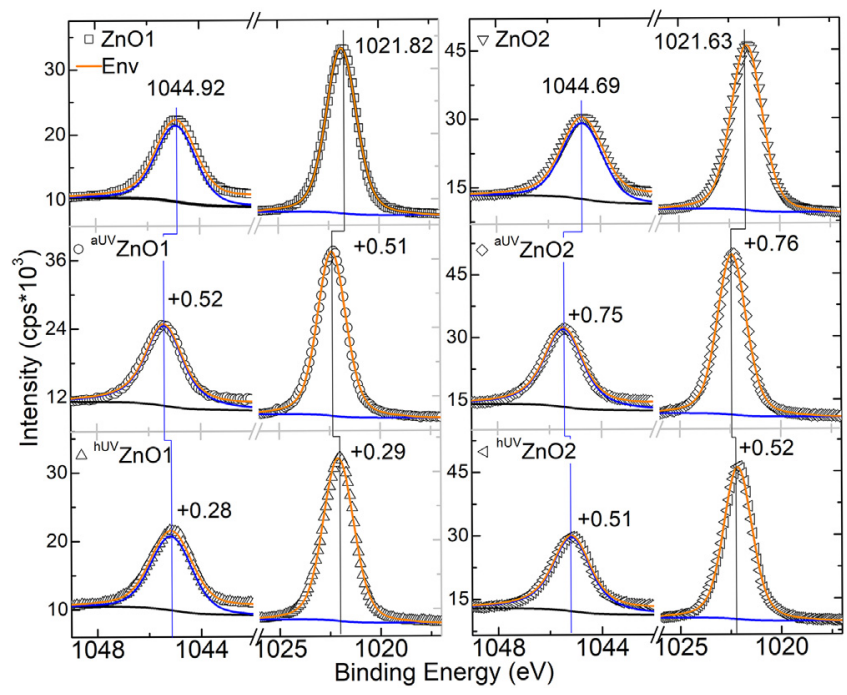

Fig. 4. $\mathrm{Zn} 2 \mathrm{p}$ core-level spectra from $\mathrm{ZnO}$ nanorods. Spectral locations of the peaks are indicated in $\mathrm{eV}$, and the shift is annotated with respect to that of pristine counterpart. 

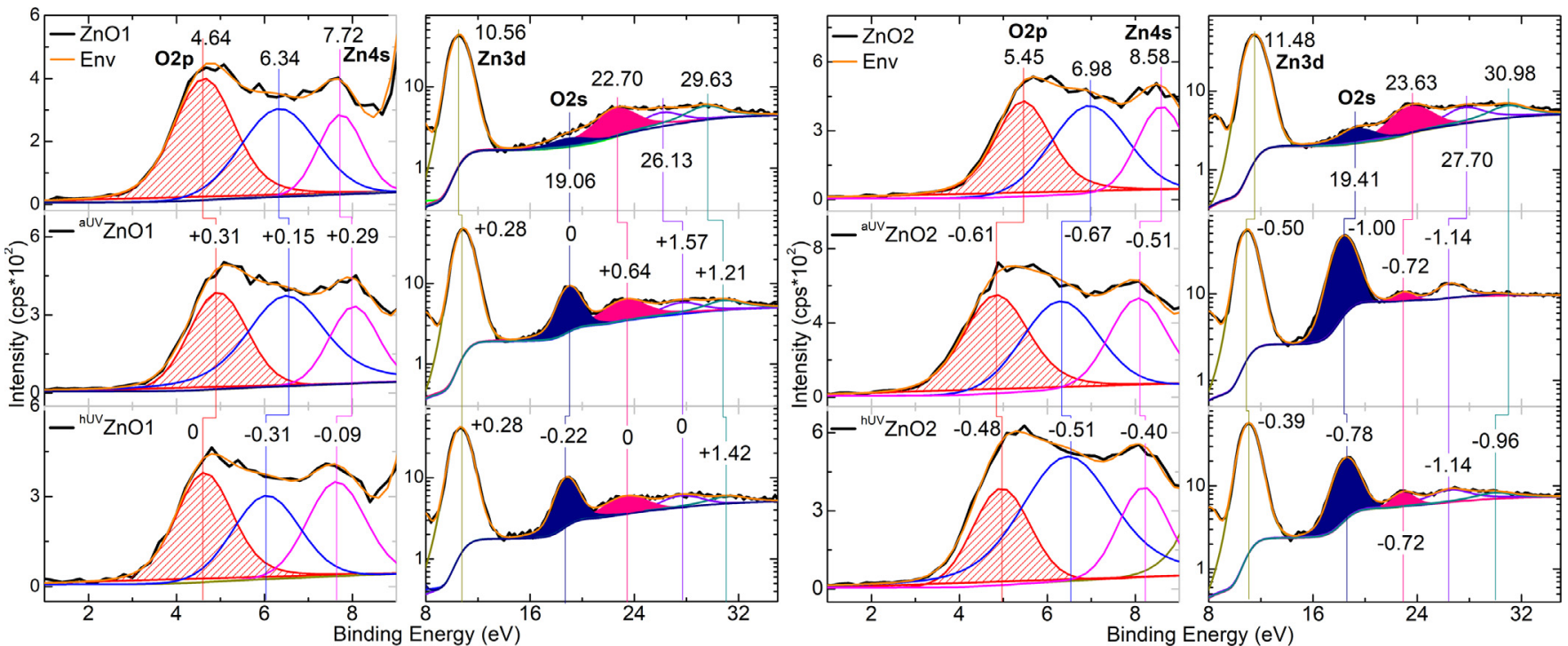

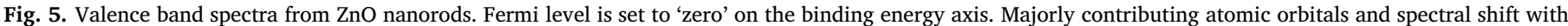
reference to the pristine samples are indicated.

increase of metallic zinc, or $\mathrm{Zn}_{i} \mathrm{~s}$. Nevertheless, we will see their presence and changes to their density in the context of bulk optical properties for both the samples.

Furthermore, we have also investigated valence band region until $35 \mathrm{eV}$ below the $E_{\mathrm{F}}$, and spectra are shown in Fig. 5 for $\mathrm{ZnO} 1$ and $\mathrm{ZnO} 2$ samples [30]. Peak positions and shift with respect to untreated samples are annotated on the spectra. The peak centers contributing to the VB edges are at 4.64 and $5.45 \mathrm{eV}$ for $\mathrm{ZnO} 1$ and $\mathrm{ZnO} 2$, respectively, where the difference is attributed to multiple factors, as discussed in the following. VB edge has a major contribution from O2p orbitals however, hybridized with Zn3d/4sp orbitals. The hybridized states extend until about $5 \mathrm{eV}$ below VB edge. The structure of VB edge is, of course dependent on the stoichiometry at the surface, where notably the surface of $\mathrm{ZnO} 2$ is slightly $\mathrm{Zn}$-rich than that of $\mathrm{ZnO} 1$ (Table 1). On the other hand, the surface defects, adsorbants and chemisorbed functional groups [25] contribute to the VB edge, where the peak at $4.64 / 5.45 \mathrm{eV}$ ( $\mathrm{ZnO1/ZnO2)} \mathrm{is} \mathrm{attributed} \mathrm{to} \mathrm{the} \mathrm{dangling} \mathrm{orbitals} \mathrm{of} \mathrm{surface} \mathrm{O}$ atoms [31]. In the previous sections, we have discussed the oxygeneous functional groups at the surface in O1s and C1s core-level spectra. By given these factors, the difference in the spectral location of peak contributing to the VB edge among the two samples is convincing. Moving away from the edge, until Zn3d band the spectral components originate from relatively sub-surface region [31], however, within the limit of the electron escape depth as discussed with reference to Fig. $1 \mathrm{f}$.

In the case of $\mathrm{ZnO1}$, upon UV-treatment the peak contributing to the VB edge is blue shifted about $0.31 \mathrm{eV}$, apart from a loss of relative intensity. In the case of pristine samples, the formation of the depletion layer at the suface bends the VB and CB (relatively) upward. Upon UV exposure, the photoholes recapture the trapped electrons reducing the bent of the band edge, see Fig. $6 \mathrm{~g}$ part (1. It must be emphasized that the surface is catalytically active upon photoexcitation, which regenerated $\mathrm{COC}$ and $\mathrm{COOH}$ functional groups, see the discussion on $\mathrm{C} 1$ s spectra. After healing, the edge recovered to a scenario that is comparable to its untreated counterpart. Also, we note an increased intensity of $\mathrm{O} 2 \mathrm{~s}$ (peak around $19 \mathrm{eV}$ ). As mentioned earlier, the higher BE peaks (lying above binding energy of $8 \mathrm{eV}$ ) occur from slightly sub-surface region of the nanorod [31]. The increased O2s intensity is a clear indication of changes to the lattice integrity/structure [32]. Nevertheless, this could have multiple origins, such as changes to the atomic composition due to the catalytic activity or the intrinsic property of the lattice and defects. For $\mathrm{ZnO}$, in sharp contrast to that of $\mathrm{ZnO}$, the VB edge shifted towards lower $\mathrm{BE}$. The chemisrobed gases leave the suface under above band gap illumination for both $\mathrm{ZnO} 1$ and $\mathrm{ZnO} 2$. However, under UVtreatment significant changes took place at the surface, where $\mathrm{ZnO} 2$ is catalytically more active than that of $\mathrm{ZnO} 1$ (see $\mathrm{O} 1 \mathrm{~s}$ and $\mathrm{C} 1 \mathrm{~s}$ spectra and discussion therein). This is reflected in an increased intensity of $\mathrm{O} 2 \mathrm{~s}$ which is relatively higher for $\mathrm{ZnO} 2$ than that of $\mathrm{ZnO} 1$ [32]. Indeed from O1s spectra of $\mathrm{ZnO} 2$ it should be noted that the $\mathrm{O}_{C h}\left(\mathrm{O}_{\mathrm{ZnO}}\right)$ component decreases (increases) after UV-treatment/healing which confirms that O2s peak has major contribution from the lattice than that of $\mathrm{O}_{\mathrm{Ch}^{-}}$ groups. In contrast, for $\mathrm{ZnO} 1$ the $\mathrm{O}_{C h}\left(\mathrm{O}_{\mathrm{ZnO}}\right)$ component depicted nominal change in the intensity. After the course of healing, the VB edge was recovered for $\mathrm{ZnO1}$ with a slight red-shift and lower intensity of O2s. For $\mathrm{ZnO} 2$ the $\mathrm{VB}$ edge depicted a net red shift of about $0.48 \mathrm{eV}$ with a slight loss of intensity from O2s. Furthermore, the peak centered at $22.7 \mathrm{eV}$ ( $\mathrm{ZnO1}$ ) depicted some blue-shift and slightly loss in its intensity upon UV-treatment. This also true for $\mathrm{ZnO} 2$ with reference to peaks at $19.4 \mathrm{eV}$. Peaks at 22.7 and $23.6 \mathrm{eV}$ are tentatively attributed to O2p and/or Zn4s atomic orbitals. Indeed, DFT like theoretical studies are required to accurately disentangle the changes to $\mathrm{O} 2 \mathrm{~s}$ with reference to $\mathrm{O} 2 \mathrm{p} / \mathrm{Zn} 4 \mathrm{~s}$. For $\mathrm{ZnO} 1$ sample, the $\mathrm{Zn3d}$ peak at $10.56 \mathrm{eV}$ depicted some blue-shift after UV-treatment and sustained its intensity and shift after healing [23]. For $\mathrm{ZnO} 2$ this feature appeared at $11.48 \mathrm{eV}$ with an appearant blue shift of about $1 \mathrm{eV}$ with respect to $\mathrm{ZnO1}$. Shift within the sample might be due to the variation in the degree of oxidation of $\mathrm{Zn}$ atom, as evidenced from the $\mathrm{O} 1 \mathrm{~s}$ and $\mathrm{Zn} 2 \mathrm{p}$ spectra. Furthermore, the formation of $\mathrm{ZnCO}_{2}-$ surface complex could be observed on surfaces with point defects after $\mathrm{CO}_{2}$ exposure at $300 \mathrm{~K}$. This surface complex is most probably the reason for the shift of $\mathrm{Zn3d}$ state, which is complimented by larger FWHM of $\mathrm{O}_{C h}$ under multidentate configuration.

\subsection{Bulk optical properties}

In the previous sections, we have discussed the effect of prolonged $\mathrm{UV}$ exposure on the surface electronic structure of $\mathrm{ZnO}$ nanorods, now we focus on a bulk optical property, namely photoluminescence which unfolds the intrinsic and radiative defect density. Fig. $6 \mathrm{a}$ and $\mathrm{b}$ depict $\mathrm{PL}$ spectra from $\mathrm{ZnO} 1$ and $\mathrm{ZnO} 2$, respectively, where the spectral locations and attributions are annotated. Free exciton recombination and various relevant defect-emissions were schematized in Fig. 6c, see Ref. [11] and citations therein. Schematic of $\mathrm{ZnO}$ crystal with various planes is shown in Fig. 6d. Here we choose a non-polar surface (10-10) for the clarity of the discussion, refer to Fig. $6 \mathrm{~d}$ for various planes. 

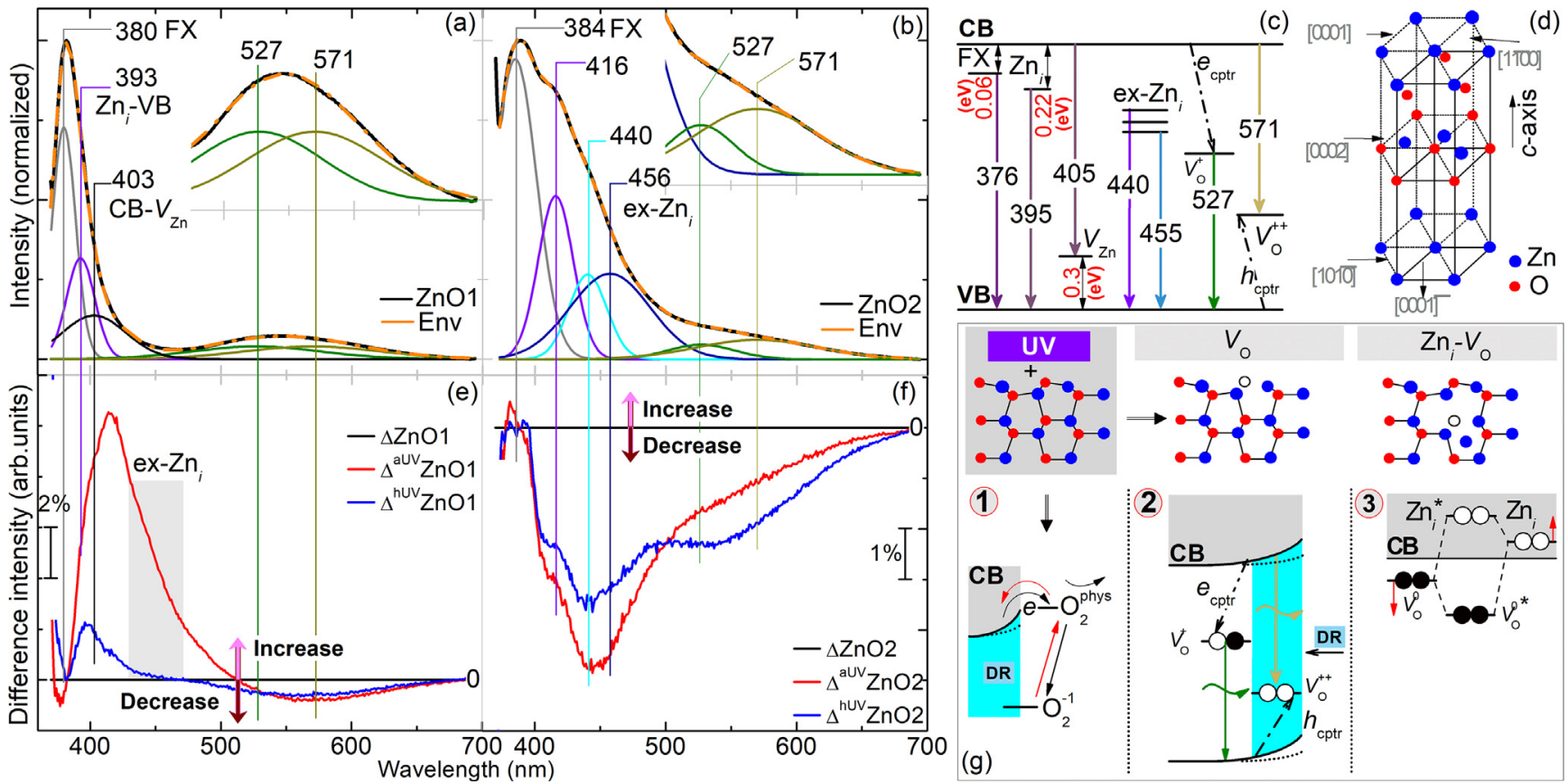

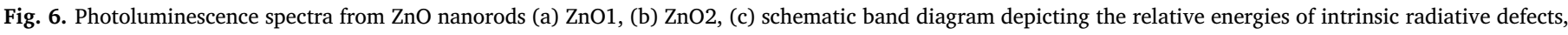

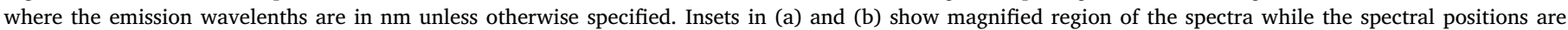

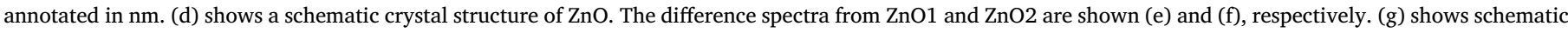
of various processes. (1) and (2) show the surface reactions for above gap excitation, while (3) indicates the attractive interaction between $\mathrm{Zn}_{i} \mathrm{~s}$ and neutral $V_{\mathrm{O}} \mathrm{S}$.

The effect of UV exposure on the PL is unveiled via difference spectra as shown in Fig. 6e and $\mathrm{f}$ for $\mathrm{ZnO} 1$ and $\mathrm{ZnO} 2$, respectively. Fig. $6 \mathrm{~g}$ (1) and (2) show surface and slightly subsurface reactions upon above band gap excitation. Part (3) depicts interaction between intrinsic defects in the bulk of the material. These schematics will be referred to in the discussion, contextually. The PL spectra were deconvoluted into 5 bands including free exciton recombination (FX) which occurred at $\sim 380$ and $\sim 384 \mathrm{~nm}$ for $\mathrm{ZnO} 1$ and $\mathrm{ZnO} 2$, respectively [11]. The other three bands are attributed to various intrinsic defects such as $\mathrm{Zn}_{i} \mathrm{~s}$, ex $-\mathrm{Zn}_{i} \mathrm{~s}, V_{\mathrm{O}} \mathrm{s}$ and/or $V_{\mathrm{Zn}} \mathrm{s}$. The differences in the spectral features are indications of variations in the defect densities for $\mathrm{ZnO} 1$ and $\mathrm{ZnO} 2$ samples [11]. The intensity ratio of interband transition to that of defect emission is an index of the optical quality of the material. Indeed, this ratio is higher for $\mathrm{ZnO} 1$ than that of $\mathrm{ZnO} 2$, suggesting better optical quality of the former.

Going into the defect related emission, we start with the green emission which is attributed to oxygen vacancies. Oxygen molecule undergoes a spontaneous and dissociative chemisorption at a oxygen vacancy site $[26,27]$. Essentially the vacancy is filled when the oxygen molecule donates one oxygen atom to the lattice at room temperature (at non-polar surfaces). These are the sites at which oxygen-assisted recombination of electrons and holes take place. This is energetically located about $0.5 \mathrm{eV}$ above the VB edge [33]. On the other hand, interestingly, hydrogen being ubiquitous in experimental conditions is also believed to occupy oxygen vacancy site (shallow donor, $\mathrm{H}_{\mathrm{O}}{ }^{+}$) and forms a multicenter bond where $\mathrm{H}$ is equally shared between the four $\mathrm{Zn}$ nearest neighbors [2]. From the neutral state (with two electrons) $V_{\mathrm{O}}$ s are ionized by donating 1 or 2 electrons to the $\mathrm{CB}$ of $\mathrm{ZnO}$ transforming themselves into $V_{\mathrm{O}}{ }^{+}$or $V_{\mathrm{O}}{ }^{++}$, respectively [34]. The emission due to charged oxygen vacancy $\left(V_{\mathrm{O}}{ }^{\delta}\right)$ consists of two components at $527 \mathrm{~nm}$ and $571 \mathrm{~nm}$ corresponding to singly $\left(527 \mathrm{~nm}: V_{\mathrm{O}}{ }^{+}+\right.$photoexcited holes) and doubly $\left(571 \mathrm{~nm}\right.$ : $\mathrm{e}_{\mathrm{CB}}+V_{\mathrm{O}}{ }^{++}$, where $\mathrm{e}_{\mathrm{CB}}$-electron from conduction band) ionized defects, respectively (Fig. 6c) $[3,4,34,35]$. Although PL from zinc oxide is believed to occur from the bulk of the sample, the green emission has some interesting characteristics $[3,4,34,35]$. Indeed, in the case of as prepared samples, the gaseous species such as $\mathrm{CO}_{2}, \mathrm{O}_{2}$ form the depletion region (DR) by capturing an electron from $\mathrm{CB}\left(\mathrm{e}_{\mathrm{cptr}}\right)$, see Fig. $6 \mathrm{~g}$ (1) and (2). For above band gap illumination, electron hole pairs are created in $\mathrm{CB}$ and VB, respectively. The increased hole-population in the VB releases the chemisorbed gases by re-capturing the electron. The removal of such electron withdrawing species decreases the width of depletion region and relatively flattens the conduction and valence bands. Interestingly, the depletion region and grain boundaries at the surface are favourable conditions for the formation of $V_{\mathrm{O}}{ }^{++}$state $[3,4,35]$, which is the case with as prepared samples. See the schematic shown in Fig. $6 \mathrm{~g}$ part (2). Importantly, after the UV-exposure we observe a loss of intensity that is relatively higher for the band centred at $571 \mathrm{~nm}$ than that of $527 \mathrm{~nm}$ (Fig. 6e and f). i.e. UV-treatment subdued the intensity of $V_{\mathrm{O}}{ }^{++}$component, via removing the chemisorbed species. In our earlier investigation, we have observed a converse phenomenon, where upon increasing the width of the depletion layer, relatively $V_{\mathrm{O}}{ }^{++}$component is increased [3]. The width of the depletion region depends on the intrinsic carrier concentration(s). For $\mathrm{ZnO} 2$, the loss of $\mathrm{V}_{\mathrm{O}}{ }^{++}$component is higher than that of $\mathrm{ZnO1}$, as seen from Fig. $6 \mathrm{f}$ and e, respectively. Also, the curves $\Delta^{\mathrm{aUV}} \mathrm{ZnO} 1$ and $\Delta^{\mathrm{hUV}} \mathrm{ZnO} 1$ in Fig. 6e indicated a trend of retrieving the original green emission intensity. This is in contrast to that of $\mathrm{ZnO} 2$, where $V_{\mathrm{O}}{ }^{++}$component further lost its intensity after healing ( $\left.\Delta^{\mathrm{aUV}} \mathrm{ZnO} 2 v s \Delta^{\mathrm{hUV}} \mathrm{ZnO} 2\right)$.

In the context of zinc-related defects, the energetic positions of $\mathrm{Zn}_{i} \mathrm{~s}$, ex- $\mathrm{Zn}_{i} \mathrm{~s}$ and the corresponding emission wavelengths are indicated in Fig. $6 \mathrm{c}$. The ex $-\mathrm{Zn}_{i}$ states can be ionized $\mathrm{Zn}_{i}$ s, complex defect or localized $\mathrm{Zn}_{i}$ states, however the origin of their formation is not completely understood yet [36]. $\mathrm{Zn}_{i}$ to VB transition occurred only in the case of $\mathrm{ZnO} 1$ sample, while $\mathrm{ZnO} 2$ exhibited $\mathrm{ex}-\mathrm{Zn}_{i}$ related defect bands. For $\mathrm{ZnO1}$, interestingly, after UV-treatment, not only the luminescence due to $\mathrm{Zn}_{i}$ is increased but also transitions from ex $-\mathrm{Zn}_{i}$ s to $\mathrm{VB}$ are observed. This indicates enhanced density of $Z_{i}$-defects and formation of new ex- $\mathrm{Zn}_{i}$ states (grey box on Fig. 6e). However, after healing, ex $-\mathrm{Zn}_{i} \mathrm{~s}$ to $\mathrm{VB}$ transitions are almost subdued, with a net increase in the $\mathrm{Zn}_{i}$ to $\mathrm{VB}$ band emission. In clear contrast to this scenario, $\mathrm{ZnO} 2$ sample significantly lost the emission intensity from ex $-\mathrm{Zn}_{i} \mathrm{~s}\left(\Delta^{\mathrm{auV}} \mathrm{ZnO}\right.$, Fig. 6f). 
Table 2

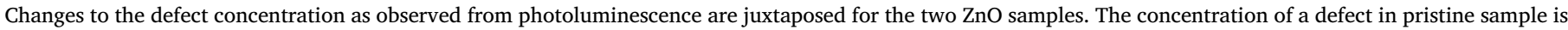
indicated in square brackets while the course of treatment is indicated with superscript aUV or hUV. Enumerated observations are discussed in the text.

\begin{tabular}{|c|c|c|c|c|c|c|}
\hline \multicolumn{3}{|c|}{ Defect/Pristine case } & \multirow{3}{*}{$\begin{array}{l}\text { After UV treatment } \\
\operatorname{aUV}_{\left[V_{\mathrm{O}}{ }^{\delta}\right]<\left[V_{\mathrm{O}}^{\delta}\right]} \\
\operatorname{aUV}_{\left[V_{\mathrm{O}}^{\delta}\right]<\left[V_{\mathrm{O}}^{\delta}\right]}\end{array}$} & \multirow{3}{*}{ 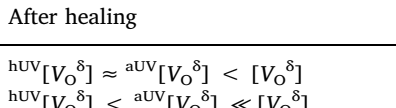 } & \multirow{2}{*}{$\begin{array}{l}\text { Net change after healing } \\
\text { Decrease }\end{array}$} & \multirow{2}{*}{$\begin{array}{l}\text { Note } \\
\text { (1) }\end{array}$} \\
\hline$\left[V_{\mathrm{O}}^{\delta}\right]$ & $\mathrm{ZnO1}$ & low & & & & \\
\hline & $\mathrm{ZnO} 2$ & low & & & Decrease & (2) \\
\hline \multirow[t]{2}{*}[\mathrm{ex}-\mathrm{Zn}_{i}]{} & $\mathrm{ZnO1}$ & $\approx 0$ & $\operatorname{aUV}^{\mathrm{a}}\left[\mathrm{ex}-\mathrm{Zn}_{i}\right] \gg\left[\mathrm{ex}-\mathrm{Zn}_{i}\right]$ & 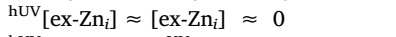 & No change & (3) \\
\hline & $\mathrm{ZnO} 2$ & high & 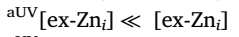 & 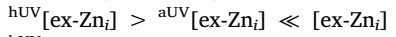 & Decrease & (4) \\
\hline \multirow[t]{2}{*}[\mathrm{Zn}_{i}]{} & $\mathrm{ZnO1}$ & low & $\operatorname{aUv}\left[\mathrm{Zn}_{i}\right] \gg\left[\mathrm{Zn}_{i}\right]$ & $\mathrm{hUV}\left[\mathrm{Zn}_{i}\right]>\left[\mathrm{Zn}_{i}\right]$ & Increase & (5) \\
\hline & $\mathrm{ZnO} 2$ & high & ${ }^{\mathrm{aUV}}\left[\mathrm{Zn}_{i}\right] \ll\left[\mathrm{Zn}_{i}\right]$ & 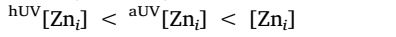 & Decreases & (6) \\
\hline
\end{tabular}

After healing in ambient, we observe a slight increase of ex- $\mathrm{Zn}_{i}$ emission, however, did not recover to its original intensity. Essentially, some of the changes are irreversible while the others continue to change over time, as discussed in the following. The changes to the defect concentrations are summarized in Table 2 for both the samples. To unveil the underlying mechanisms behind the non-retrieval and/or the trends of retrieved intensities from $V_{\mathrm{O}}, \mathrm{Zn}_{i}, \mathrm{ex}-\mathrm{Zn}_{i}$-related emission, deeper understanding of the interaction between these defects is essential. Generally, the intrinsic donor defects such as $V_{\mathrm{O}} \mathrm{S}$ and $\mathrm{Zn}_{i} \mathrm{~s}$ are predominantly ionic in nature which are formed due to Schottky and Frenkel reactions (followed by ionization), respectively [36]. $V_{\mathrm{O}}$ and $\mathrm{Zn}_{i}$ mainly originate from the $\mathrm{Zn} 4 \mathrm{~s}$ orbitals, where the former may be occupied by molecular oxygen or hydrogen $[2,26,27]$. Notably, $\mathrm{Zn}_{i} \mathrm{~S}$ occupy octahedral sites [37], where the interstitial volume is higher to accommodate the $\mathrm{Zn}$ atom. Indeed, there are three equivalent octahedral sites around a $V_{\mathrm{O}}$, which are spacious to accommodate the interstitial atoms and hence preferable sites for $\mathrm{Zn}_{i} \mathrm{~s}$. Both being donor type, $\mathrm{Zn}_{i}$ is attracted by neutral $V_{\mathrm{O}}$ via quantum mechanical hybridization between the respective electronic states as predicted by theory (see (3) in Fig. $6 g$ ) $[38,39]$. i.e. in charged state they are under Coulombic repulsion if nearby. As the distance between two defects decreases, the interaction significantly lowers the energy of the electronic donor orbital of $V_{\mathrm{O}}$ and the total energy of the system. Furthermore, for $\mathrm{Zn}_{i}-V_{\mathrm{O}}$ pair the tensile and compressive strains are compensated which further supports a weak attractive interaction. Notably, the attractive interaction from the compensated-strain is weaker than that of quantum mechanical hybridization [38].

From the PL spectra, it is clear that the concentration of charged oxygen vacancy $\left(\left[V_{\mathrm{O}}{ }^{\delta}\right]\right)$ is certainly lowered as a consequence of UVtreatment (Table 1 and 2). Also, changes to the concentration of other intrinsic defects after the UV-treatment can be temporary or permanent, where in general, lattice stabilizes with some density of intrinsic defects while maintaining the charge neutrality. By given this background, our observations are enumerated in Table 2 and discussed in the following.

(1) Desorption of chemisorbed species and decreased $\left[V_{O}{ }^{\delta}\right]$ at the surface, as consistent with the intensity of $\mathrm{O}_{\mathrm{ZnO}}(\mathrm{O} 1 \mathrm{~s}$ spectra).

(2) For the above band gap excitation, the catalytic activity of the surface not only decreased the $\left[V_{\mathrm{O}}{ }^{\delta}\right]$ but also improved the intensity of $\mathrm{O}_{\mathrm{ZnO}}\left(\mathrm{O} 1 \mathrm{~s}\right.$ spectra). After healing, the intensity of $\mathrm{O}_{\mathrm{ZnO}} / \mathrm{O} 1 \mathrm{~s}$ further increased, which is consistent with the further loss of $V_{O}{ }^{\delta}$ related emission. Note that the $V_{\mathrm{O}} \mathrm{s}$ can be excited to a metastable charged state after a structural relaxation while a thermally activated barrier prevents the recapture of electrons [40]. The structural relaxation after defect reorganization determines the final density of defects.

(3) ${ }^{\mathrm{aUV}}\left[\mathrm{ex}-\mathrm{Zn}_{i}\right]$ is a temporary response of the lattice due to the fluctuations in the $\left[V_{\mathrm{O}}{ }^{\delta}\right]$. The Fermi level in the bulk determines the degree of ionization of $V_{\mathrm{O}} \mathrm{S}$ at the surface for a constant surface $\left[V_{\mathrm{O}}\right]$ [41]. In this case, the $\left[V_{O}\right]$ is decreased due to UV-treatment which effected the carrier concentration. This essentially changed the degree of ionization and perhaps increased the neutral $\left[V_{O}\right]$. Now the previously discussed attractive interaction between $\mathrm{Zn}_{i} \mathrm{~s}$ and $V_{\mathrm{O}} \mathrm{s}$ should be considered, which may mediate the stabilization of $\mathrm{Zn}_{i} \mathrm{~s}$ around neutral $V_{\mathrm{O}} \mathrm{S}$. Most probably, the lattice recovery/ reconstruction may take place on slower time scales preceded by the decreased defect concentration at the surface. This might happen via already existing $\mathrm{H}_{i}^{+}$which binds with $\mathrm{O}$ in the $\mathrm{ZnO}$ lattice (see the discussion on O1s) [2] and/or diffusion of hydrogen in and out of the lattice (see Refs. 51-54 in Ref. [2]). This $\mathrm{H}_{i}^{+}$is notably less stable than that of substituted counterpart at a $V_{\mathrm{O}}$ site, the $\mathrm{H}_{\mathrm{O}}{ }^{+}$. Also note that the $\mathrm{H}_{i}{ }^{+}$causes significant lattice relaxation in both bond-centre (BC) and $\mathrm{ABO}$ configurations. Especially, in $\mathrm{BC}$ configuration the $\mathrm{Zn}$ and $\mathrm{O}$ atoms move outward as much as $40 \%$ and $20 \%$ of the bond lengths, respectively. ABO configuration causes relaxation about $20 \%$ of the bond length for both the $\mathrm{Zn}$ and $\mathrm{O}$ atoms. Since $\mathrm{H}_{i}{ }^{+}$can occur in rather high concentrations, it leads to the formation of $\mathrm{Zn}_{i}$ s followed by ex- $\mathrm{Zn}_{i}$ due to excessively high lattice distortion. However, after healing, the lattice further stabilizes via minimizing the ex- $\mathrm{Zn}_{i} \mathrm{~s}$ and $\mathrm{Zn}_{i} \mathrm{~s}$.

(4) $\mathrm{ZnO} 2$ depicted rather high levels of interstitial $\mathrm{Zn}$ which under catalytic reaction were oxidized (upon above gap illumination). This is explicit from the intensity of $\mathrm{O}_{\mathrm{ZnO}}(\mathrm{O} 1 \mathrm{~s}$ spectra) and the blue shift of $\mathrm{Zn} 2 \mathrm{p}$ spectra. Hence, the subdued $\mathrm{ex}-\mathrm{Zn}_{i}$ related emission is convincing as $\mathrm{Zn}_{i} \mathrm{~s}$ are decreased. After the healing process, this emission is slightly recovered.

(5)/(6) The explanation given in point (3)/(4) in the context of ex$\mathrm{Zn}_{i} \mathrm{~s}$ is also true for $\mathrm{Zn}_{i} \mathrm{~s}$ as the former can be ionized $\mathrm{Zn}_{i} \mathrm{~s}$, complex defect or localized $\mathrm{Zn}_{i}$ states [36].

\section{Conclusions}

This study unviels reversible and irreversible changes to the electronic structure of $\mathrm{ZnO}$ due to prolonged above band gap illumination. Here we choose nanorods of zinc oxide by given the higher surface area to volume ratio to enhance any surface/bulk effects due to above band gap illumination. We grew ZnO nanorods on PET/ITO substrate via electrodeposition. The width of the synthesized nanorods were in the range of $180-240 \mathrm{~nm}$ with a wurtzite crystal structure. HRTEM depicted well defined lattice planes and growth along the $c$-axis of $\mathrm{ZnO}$. The surfaces of $\mathrm{ZnO} 1$ and $\mathrm{ZnO} 2$ were zinc rich, however, the latter has slightly higher zinc content. As prepared surfaces consisted of CC, COC and $\mathrm{COOH}$ groups. Upon UV-treatment, we found some regeneration of COC groups on the suface with an overall decrease in the carbon content. Specifically, the surface of $\mathrm{ZnO} 2$ was catalytically more active to produce $\mathrm{COC}$ functional groups than that of $\mathrm{ZnO}$. We have also observed systematic changes to the ionic nature of the surface where after UV-treatment the oxygeneous functional groups bind strongly to the suface. O1s spectra revealed some significant quantities of chemisorbed oxygen of various types (also complimented by C1s spectra). Multidentate surface complexes and other functional groups contributed to the relatively high FWHM of the peak corresponding to $\mathrm{O}_{C h}$. Severe changes to the VB edge were indicative of desorption of some chemisorbed species in the case of $\mathrm{ZnO} 1$, and complex formation in the case of $\mathrm{ZnO} 2$. Also, importantly after the UV-treatment, the catalytic activity of the surface increased the fraction of the lattice oxygen, $\mathrm{O}_{\mathrm{ZnO}}$. 
Furthermore, zinc rich surfaces were oxidized upon above band gap excitation due to the intrinsic surface/defect mediated catalytic activity. Deeper VB structure indicated an increased contribution of O2s orbitals, corroborating the changes to the VB edge as well as the observations in $\mathrm{O} 1 \mathrm{~s}$ spectra. It was clear at the end of healing process that the changes to the deeper VB are irreversible. The VB edge for $\mathrm{ZnO} 1$ recovered to its pristine condition unlike $\mathrm{ZnO}$. It is convincing by given the fact that $\mathrm{ZnO} 2$ is catalytically more active and changes were severe than that of $\mathrm{ZnO}$.

Investigation on the bulk optical properties revealed the effect of above band gap excitation is just not limited to the surface, but rather influences the bulk of the lattice and intrinsic defect equilibrium. Upon UV-treatment, we have observed a loss in the intensity of the PL bands corresponding to $V_{\mathrm{O}}{ }^{\delta}$ which is consistent with the desorption of surface chemisorbed species and decresed thickness of the depletion layer. In the case of $\mathrm{ZnO1}$, the emission from ex- $\mathrm{Zn}_{i} \mathrm{~s}$ appeared after UV-treatment which was subdued in the course of healing. After healing, $\mathrm{ZnO1}$ sustained the emission from $\mathrm{Zn}_{i} \mathrm{~s}$. On the contrary, $\mathrm{ZnO} 2$ depicted rather peculiar behavior. After UV-treatment, severe loss of ex- $\mathrm{Zn}_{i}$ related emission was observed, which is consistent with the observation from XPS. When $\mathrm{ZnO} 2$ left for healing, a slight increase in the emission from ex- $Z n_{i}$ was observed with a further loss of $V_{O}{ }^{8}$ related emission. The slow recovery and reorganization of intrinsic defects were attributed to the diffusivity of $\mathrm{H}_{i}{ }^{+}$and the associated lattice distortion. Furthermore, the attractive interaction between neutral $V_{\mathrm{O}} \mathrm{s}$ and $\mathrm{Zn}_{i} \mathrm{~s}$ also believed to mediate the migration of defects and subsequent stabilization. These findings related to altercations to the defect equilibrium under above band gap excitation are fundamentally important due to the applicability of $\mathrm{ZnO}$ based nanostructures in optoelectronic applications.

\section{Acknowledgment}

SV would like to thank TUBITAK BIDEB 2221 Fellowships for Visiting Scientists and Scientists on Sabbatical for a postdoctoral fellowship, 2014.

\section{References}

[1] J. Liu, M.D. Rojas-Andrade, G. Chata, Y. Peng, G. Roseman, J.-E. Lu, G.L. Millhauser, C. Saltikov, S. Chen, Photo-enhanced antibacterial activity of ZnO/ graphene quantum dot nanocomposites, Nanoscale 10 (2018) 158-166.

[2] A. Janotti, C.G.V. Walle, Fundamentals of zinc oxide as a semiconductor, Rep. Prog. Phys. 72 (2009) 126501.

[3] S. Vempati, A. Celebioglu, T. Uyar, Defect related emission versus intersystem crossing: blue emitting $\mathrm{ZnO} /$ graphene oxide quantum dots, Nanoscale 7 (2015) 16110.

[4] S. Vempati, S. Chirakkara, J. Mitra, P. Dawson, K.K. Nanda, S.B. Krupanidhi, Unusual photoresponse of indium doped $\mathrm{ZnO}$ /organic thin film heterojunction, Appl. Phys. Lett. 100 (2012) 162104.

[5] S.Y. Sawant, J.Y. Kim, H.T. Hiep, S.A. Ansari, M.H. Cho, Electrochemically active biofilm-assisted biogenic synthesis of Ag-decorated ZnO@C core-shell ternary plasmonic photocatalyst with enhanced visible-photocatalytic activity, New J. Chem. (2017).

[6] Y. Wang, R. Kováčik, B. Meyer, K. Kotsis, D. Stodt, V. Staemmler, H. Qiu, F. Traeger, D. Langenberg, M. Muhler, C. Wöll, $\mathrm{CO}_{2}$ activation by $\mathrm{ZnO}$ through the formation of an unusual tridentate surface carbonate, Angew. Chem. Int. Ed 46 (2007) 5624.

[7] F. Kayaci, S. Vempati, C.O-. Akgun, N. Biyikli, T. Uyar, Enhanced photocatalytic activity of homoassembled $\mathrm{ZnO}$ nanostructures on electrospun polymeric nanofibers: a combinationof atomic layer deposition and hydrothermal growth, Appl. Catal. B 156-157 (2014) 173-183.

[8] F. Kayaci, S. Vempati, I. Donmez, N. Biyikli, T. Uyar, Role of zinc interstitials and oxygen vacancies of $\mathrm{ZnO}$ in photocatalysis: a bottom-up approach to control defect density, Nanoscale 6 (2014) 10224-10234.

[9] F. Kayaci, S. Vempati, C.O. Akgun, I. Donmez, N. Biyikli, T. Uyar, Transformation of polymer-ZnO core-shell nanofibers into $\mathrm{ZnO}$ hollow nanofibers: Intrinsic defect reorganization in $\mathrm{ZnO}$ and its influence on the photocatalysis, Appl. Catal. B. 176-177 (2015) 646-653.

[10] M.R. Hoffmann, S.T. Martin, W. Choi, D. Bahnemann, Environmental applications of semiconductor photocatalysis, Chem. Rev. 95 (1995) 69-96.

[11] S. Vempati, J. Mitra, P. Dawson, One-step synthesis of ZnO nanosheets: a blue-white fluorophore, Nanoscale Res. Lett. 7 (2012) 470.

[12] R.J. Collins, D.G. Thomas, Photoconduction and surface effects with zinc oxide crystal, Phys. Rev. 112 (1958) 388.

[13] J. Bao, I. Shalish, Z. Su, R. Gurwitz, F. Capasso, X. Wang, Z. Ren, Photoinduced oxygen release and persistent photoconductivity in ZnO nanowires, Nanoscale Res. Lett. 6 (2011) 1.

[14] S.A. Studenikin, N. Golego, M. Cocivera, Carrier mobility and density contributions to photoconductivity transients in polycrystalline ZnO films, J. Appl. Phys. 87 (2000) 2413.

[15] P. Sharma, K. Sreenivas, K.V. Rao, Analysis of ultraviolet photoconductivity in ZnO films prepared by unbalanced magnetron sputtering, J. Appl. Phys. 93 (2003) 3963-3970.

[16] J. Reemts, A. Kittel, Persistent photoconductivity in highly porous ZnO films, J. Appl. Phys. 101 (2007) 013709.

[17] D.A. Melnick, Zinc oxide photoconduction, an oxygene adsorption process, J. Chem. Phys. 26 (1957) 1136-1146.

[18] B. Claflin, D.C. Look, D.R. Norton, Changes in electrical characteristics of ZnO Thin Films Due to Environmental Factors, J. Electron. Mater. 36 (2007) 442-445.

[19] R. Gurwitz, R. Cohen, I. Shalish, Interaction of light with the ZnO surface: photon induced oxygen "breathing", oxygen vacancies, persistent photoconductivity, and persistent photovoltage, J. Appl. Phys. 115 (2014) 033701.

[20] Y.-Y. Lin, C.-W. Chen, W.-C. Yen, W.-F. Su, C.-H. Ku, J.-J. Wu, Near-ultraviolet photodetector based on hybrid polymer/zinc oxide nanorods by low-temperature solution processes, Appl. Phys. Lett. 92 (2008) 233301.

[21] S. Hüfner, Photoelectron Spectroscopy: Principles and Applications, Springer, Berlin Heidelberg, Berlin, Heidelberg, 1996.

[22] G.E. Jellison, L.A. Boatner, Optical functions of uniaxial $\mathrm{ZnO}$ determined by generalized ellipsometry, Phys. Rev. B 58 (1998) 3586.

[23] A.V. Naumkin, A.K-. Vass, S.W. Gaarenstroom, C.J. Powell, NIST X-ray Photoelectron Spectroscopy Database, Version 4.1, in: U.S. Secretary of Commerce, 2012.

[24] Y. Shapira, S.M. Cox, D. Lichtman, Chemisorption, photodesorption and conductivity measurements on ZnO surfaces, Surf. Sci. 54 (1976) 43-59.

[25] V.E. Henrich, P.A. Cox, The Surface Science of Metal Oxides, Cambridge University Press, Cambridge, 1996

[26] W. An, X. Wu, X.C. Zeng, Adsorption of $\mathrm{O}_{2}, \mathrm{H}_{2}, \mathrm{CO}, \mathrm{NH}_{3}$, and $\mathrm{NO}_{2}$ on $\mathrm{ZnO}$ nanotube: a density functional theory study, J. Phys. Chem. C 112 (2008) 5747-5757.

[27] Y. Yan, M.M. Al-Jassim, Oxygen-vacancy mediated adsorption and reactions of molecular oxygen on the ZnO(10-10) surface, Phys. Rev. B 72 (2005) 235406.

[28] C.T. Au, W. Hirsch, W. Hirschwald, Adsorption and interaction of carbon dioxide, formic acid and hydrogen/carbon dioxide mixtures on (10-10) zinc oxide surfaces studied by photoelectron spectroscopy (XPS and UPS), Surf. Sci. 199 (1988) 507-517.

[29] W. Hotan, W. Göpel, R. Haul, Interaction of $\mathrm{CO} 2$ and co with nonpolar zinc oxide surfaces, Surf. Sci. 83 (1979) 162-180.

[30] We have recorded angle integrated photoelectron spectrum that was an average from the almost vertically standing nanorods of various planes, see Figure $6 \mathrm{~d}$.

[31] K. Ozawa, K. Sawada, Y. Shirotori, K. Edamoto, Angle-resolved photoemission study of the valence band structure of $\mathrm{ZnO}(10-10)$, J. Phys.: Condens. Matter 17 (2005) 1271-1278.

[32] We have tantatively attributed O2s to the lattice oxygen based on an indirect support that we obtained from photoluminescence, where the oxygen vacancies are in fact decreased after UV treatment. However, further studies, e.g. angle resolved photoelectron spectroscopy, are required to disentangle if the O2s states occur from $\mathrm{COC}$ and or $\mathrm{COOH}$ groups that were at the surface. See Ref. 31.

[33] J.D. Prades, A. Cirera, J.R. Morante, A. Cornet, Ab initio insights into the visible luminescent properties of ZnO, Thin Solid Films 515 (2007) 8670-8673.

[34] A. Janotti, C.G.V. deWalle, Oxygen vacancies in ZnO, Appl. Phys. Lett. 87 (2005) 122102.

[35] J.D. Ye, S.L. Gu, F. Oin, S.M. Zhu, S.M. Liu, X. Zhou, W. Liu, L.Q. Hu, R. Zhang, Y. Shi, Y.D. Zheng, Correlation between green luminescence and morphology evolution of ZnO films, Appl. Phys. A: Mater. Sci. Process 81 (2005) 759.

[36] H. Zeng, G. Duan, Y. Li, S. Yang, X. Xu, W. Cai, Blue Luminescence of ZnO nanoparticles based on non-equilibrium processes: defect origins and emission controls, Adv. Funct. Mater. 20 (2010) 561.

[37] A. Janotti, C.G.V.d. Walle, Native point defects in ZnO, Phys. Rev. B 76 (2007) 165202.

[38] Y.-S. Kim, C.H. Park, Rich variety of defects in $\mathrm{ZnO}$ via an attractive interaction between $\mathrm{O}$ vacancies and $\mathrm{Zn}$ interstitials: Origin of n-type doping, Phys Rev Lett 102 (2009) 086403.

[39] $\mathrm{Zn}_{i}$ was shown to be inside the $\mathrm{CB}$ of $\mathrm{ZnO}$ for high level of donor defect density which determines the Fermi level. However it could exist about $0.22 \mathrm{eV}$ below the CB minimum depending on the Fermi level (see cross references 28 and 29 Ref. 11).

[40] S. Lany, A. Zunger, Anion vacancies as a source of persistent photoconductivity in II-VI and chalcopyrite semiconductors, Phys. Rev. B 72 (2005) 035215.

[41] W. Göpel, Reactions of oxygen with ZnO-1010-surfaces, J. Vac. Sci. Technol. 15 (1978) 1298-1310. 